\title{
IDÉIAS
}

\section{Uma experiência de concurso público}

\section{Gilberto Tristão (*)}

$\mathrm{H}$ á cinqüenta anos, a Lei no 284 , de 28 de outubro de 1936, tratava pela primeira vez do sistema do mérito na Administração Federal. Esse evento induz a avaliar o recrutamento por mérito na Administração Pública em 1986/87.

O Decreto n: 91.403 , de 5 de julho de 1985 , proibiu o ingresso de pessoal, a qualquer titulo, na Administração Direta, bem como nas autarquias sujeitas ao regime da Lei n. 5.645, de 10 de dezembro de 1970. Assim sendo, o Poder Executivo ficou limitado às contrataçōes de servidores permitidas por decretos especificos que autorizavam a medida em caráter de excepcionalidade. As melhores oportunidades para obter emprego, em função do mérito do candidato, ocorreram no àmbito dos Poderes Legislativo e Judiciário.

O Tribunal de Contas da União realizou concurso público de provas para provimento de cargos da série de classes de Técnico de Controle Externo. Ele foi constituido de 3 (três) provas: (1) prova de Conhecimentos Gerais, que constou de questōes de Matemática e Português; (2) prova de Conhecimentos Especiais, em nivel superior, abrangendo questões objetivas de Direito, Economia, Contabilidade e Administração; e (3) prova de Conhecimientos Especificos, em nivel superior, com questōes objetivas de Técnica de Controle Financeiro e Orçamentário. Todas as provas eram eliminatórias, cada uma valendo cem pontos e sendo o minimo admitido para habilitação de cinqüenta pontos. Atribuiu-se às provas os seguintes pesos: (1) Conhecimen-

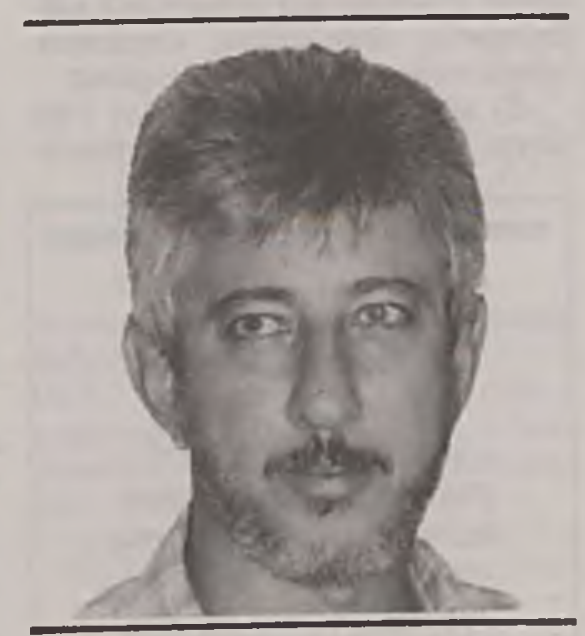

tos Gerais, peso dois; (2) Conhecimentos Especiais, peso quatro; e (3) Conhecimentos Especificos, peso quatro.

A Câmara dos Deputados está realizando concurso publico para Técnico em Material e Património. Ele compreenderá 5 (cinco) provas: (1) Legislação da Câmara dos Deputados - peso 1; (2) Conhecimentos Básicos - Matemática, Estatistica, Contabilidade e Orçamento Público - peso 2: (3) Lingua Portuguesa - peso $2 ;$ (4) Conhecimentos Especificos - Administração e Legislação de Material e Património-peso 4; (5) Datilografia -- peso 1. Todas as provas serão eliminatórias, totalizando cada uma cem pontos e exigindo-se a nota minima de sessenta pontos para aprovação.

O Tribunal de Contas do Distrito Federal abriu as inscriçōes, em dezembro de 1986, para o concurso público destinado ao provimento de cargo de Auditor. Ele consistirá de 6 (seis) provas escritas, 1 (uma) oral e 1 (uma) de titulos. Das provas escritas, quatro serão eliminatórias - (1) Direito Financeiro; (2) Direito Administrativo; (3) Direito Constitucional; (4) Contabilidade; e duas classificatórias - (5) Economia e Administração Pública; e (6) Direito Civil, Penal e Comercial. As provas escritas, oral e de títulos valerão até dez pontos cada. Só serão considerados aprovados nas provas escritas os candidatos que obtiverem: em cada prova eliminatória, nota igual ou superior a cinco pontos; e pelo menos seis pontos na média aritmétical das provas escritas. Os criterios da prova oral só serão fixados após a conclusão das provas escritas. E as 8 (oito) provas terào peso igual.

A titulo de exemplificação será apresentada, respondida e comentada a prova de Conhecimentos Especificos do concurso público para Técnico de Controle Externo do Tribunal de Contas da União, que constou de questōes objetivas sobre matéria financeira e orçamentária. No intuito de sistematizar o tratamento do assunto, as questōes foram grupadas sob temas especificos.

I-Questōes sobre Plano Nacional de Desenvolvimento:

I.1 - De acordo com a legislação vigente (Atos Complementares nos $43 / 69$ e 76/69) os Planos Nacionais de Desenvolvimento são:

a) elaborados pelo Poder Executivo e submetidos à deliberação do Congresso Nacional;

b) elaborados pela Secretaria de Planos e Orçamento do Ministério da Fazenda e aprovados pelo Presidente da República no âmbito do Conselho de Desenvolvimento Económico; 


\section{IDÉIAS}

c) elaborados pela Secretaria de Planejamento da Presidência da República e aprovados pelo Conselho Monetário Nacional;

d) elaborados pelo Conselho de Desenvolvimento Económico e aprovados pelo Ministro da Fazenda.

RESPOSTA: Alternativa $a$.

$\mathrm{O}$ candidato deveria conhecer a nova redação dada ao Art. 1.0 do Ato Complementar no 43/69 pelo Art. 1 . do A to Complementar n? 76/69, que determina: "O Poder Executivo elaborará Planos Nacionais de Desenvolvimento, de duração igual à do mandato do Presidente da República, os quais serão submetidos à deliberação do Congresso Nacional até 15 de setembro do primeiro ano do mandato presidencial".

A essência dessa questão é o controle externo do Executivo pelo Poder Legislativo, que não foi explorada pelas demais alternativas para não gerar confusāo.

II - Questões sobre Orçamento Plurianual de Investimentos:

II.1 - Pelo Ato Complementar n. 43/69 o Orçamento Plurianual de Investimentos - OPI deve conter, exclusivamente, as despesas relativas a:

a) Investimentos, Inversões Financeiras e Transferências Correntes.

b) Investimentos, Operaçōes de Crédito e Transferências de Capital.

c) Inversões Financeiras, Despesas de Custeio e Encargos da Divida Pública.

d) Investimentos, Inversōes $\mathrm{Fi}$ nanceiras e Transferèncias de $\mathrm{Ca}$ pital.

RESPOSTA: Alternativa $d$.

O Art. 5: do Ato Complementar n. 43/69 diz: "Respeitadas as diretrizes e objetivos do Plano Nacional de Desenvolvimento, o Orçamento Plurianual de Investimentos, que abrangerá periodo de três anos, considerará exclusivamente as despesas de capital".

Além disso, era necessário saber que a Classificaçào Econômica é dividida em duas Categorias Econòmicas: Despesas Correntes e Despesas de Capital. E que as Despesas de Capital subdividem-se em três Subcategorias Económicas: Investimentos, Inversões Financeiras e Transferências de Capital.

O conhecimento de que as Despesas Correntes subdividem-se em Despesas de Custeio e Transferências
Correntes permitiria eliminar as alternativas $a$ e $c$.

A alternativa $b$ é descartada porque as Operações de Crédito integram as Receitas de Capital.

III - Questōes sobre OrçamentoPrograma:

III.1 - O Orçamento Geral da Uniāo é um Orçamento-Programa porque:

a) estima as receitas e fixa as despesas para um exercício financeiro;

b) incorpora as receitas e as despesas dos órgãos da Administração Indireta;

c) as despesas são fixadas para serem aplicadas nas categorias e subcategorias económicas; elementos, subelementos e itens de despesas.

d) as despesas são fixadas para serem aplicadas nas funções, progra-

\begin{tabular}{c}
\hline Há 50 anos era pela \\
primeira vez \\
tratado o sistema \\
do mérito para o \\
acesso ao serviço \\
público. Esse evento \\
induz a avaliar como \\
está sendo feito o \\
recrutamento agora, \\
e vamos mostrar como \\
se faz concurso \\
para o TCU.
\end{tabular}

mas, subprogramas, projetos ou atividades governamentais.

RESPOSTA: Alternativa $d$.

A inovação principal do orçamento-programa consistiu na classificaçào orçamentária por objetivos, a qual, em nosso Pais, é denominada Classificação Funcional-Programática. Ela estabeleceu quatro niveis de agregação de objetivos: Funçōes/ Programas/ Subprogramas/ Projetos ou Atividades.

As alternativas $a, b$ e $c$ se aplicam ao orçamento tradicional.

IV - Questōes sobre Classificaçōes Orçamentárias:

IV.1 - Classificação Funcional-Programática:

IV.1.1 - De acordo com a classificação funcional-programática, o maior agregado das açōes do governo é:

a) a categoria económica;

b) o programa; c) a função;

d) o subprograma.

RESPOSTA: Alternativa $c$.

A alternativa $a$ é facilmente descartada porque a categoria econômica não integra a Classificação Funcional-Programática mas, sim, a Classificação Económica.

De acordo com a Classificação Funcional-Programática as ações do governo são classificadas em projetos ou atividades, que são agregados em subprogramas, os quais agregam-se em programas, por sua vez agregados em funçōes.

IV.1.2 - Nos programas de trabalho inseridos no Orçamento Geral da União os projetos e as atividades estão diretamente vinculados aos:
a) subprogramas;
b) programas;
c) elementos de despesas;
d) subelementos de despesas.

RESPOSTA: Alternativa $a$.

Os programas são desdobrados em subprogramas, aos quais se vinculam os projetos e atividades.

As altemativas $c$ e $d$ são eliminadas porque os elementos e subelementos de despesas integram a Classificação Económica e por Objeto de Gasto, enquanto os programas de trabalhos estão identificados na Classificação Funcional-Programática.

IV.2 - Classificação Económica RECEITA

IV.2.1 - O Imposto sobre Serviços de Comunicaçōes pertence ao grupo denominado:

a) Imposto sobre o Patrimônio e a Renda.

b) Imposto sobre a Produção e a Circulação.

c) Impostos Especiais.

d) Impostos Extraordinários.

RESPOSTA: Alternativa $b$.

Os IMPOSTOS subdividem-se em 5 (cinco) rubricas: Imposto sobre o Comércio Exterior, Impostos sobre - Património e a Renda, Impostos sobre a Produção e a Circulação, Impostos Especiais e Impostos Extraordinários.

O Imposto sobre Serviços de Comunicações é uma alínea dos Impostos sobre a Produção e a Circulação. IV.2.2 - O Imposto Único sobre Minerais pertence ao grupo denominado:

a) Impos tos sobre o Património e a Renda.

b) Impostos sobre a Produção e a Circulação.

c) Impostos Especiais.

d) Impostos Extraordinários. 


\section{IDÉIAS}

RESPOSTA: Alternativa $c$.

O Imposto Único sobre Mineraisé uma alinea dos Impostos Especiais. IV.2.3 - A receita orçamentária proveniente de um empréstimo tomado pelo governo é classificada na subcategoria econômica denominada:

a) Receita Patrimonial.

b) Transferências de Capital.

c) Amortização de Empréstimos.

d) Operaçōes de Crédito.

RESPOSTA: Alternativa $d$.

O Ementário da Classificação da Receita (publicado pela Secretaria de Orçamento e Finanças no Manual Técnico de Orçamento, MTO-03, 3a ed., 1985, às págs. 123-141) conceitua Operações de Crédito como "recursos decorrentes da colocação de títulos públicos ou empréstimos obtidos junto a entidades estatais ou particulares internas ou externas".

IV 2.4 - O recurso financeiro doado ao governo brasileiro, por uma instituição privada, para construção de hospitais, é uma receita que vai compor a subcategoria económica denominada:
a) Receita Patrimonial.
b) Operações de Crédito.
c) Transferências Correntes.
d) Transferencias de Capital.

RESPOSTA: Alternativa $d$.

O Ementário da Classificação da Receita conceitua Transferências de Capital como "Recursos recebidos de outras pessoas de direito publico ou privado, independente de contraprestação direta em bens e serviços. Podem ocorrer a nivel Intragovemamental e Intergovernamental, assim como recebidos de Instituições Privadas, do Exterior e de Pessoas".

A alternativa $c$ é eliminada porque as Transferências Correntes devem ser aplicadas em Despesas Correntes e a construção de hospitais classificase como Despesa de Capital.

IV.3 - Classificação Econômica DESPESA

IV.3.1 - As despesas do governo com a constituição ou o aumento de capital de empresas comerciais ou financeiras são classificadas na subcategoria economica denominada:

a) Despesas de Custeio.

b) Transferencias de Capital.

c) Inversões Financeiras.

d) Investimentos.

RESPOSTA: Alternativa $c$.

De acordo com a Portaria SOF No 8/85. A alternativa $d$ é eliminada porque, segundo a Portaria SOF mencionada, Investimentos asseguram recursos para Constituição ou

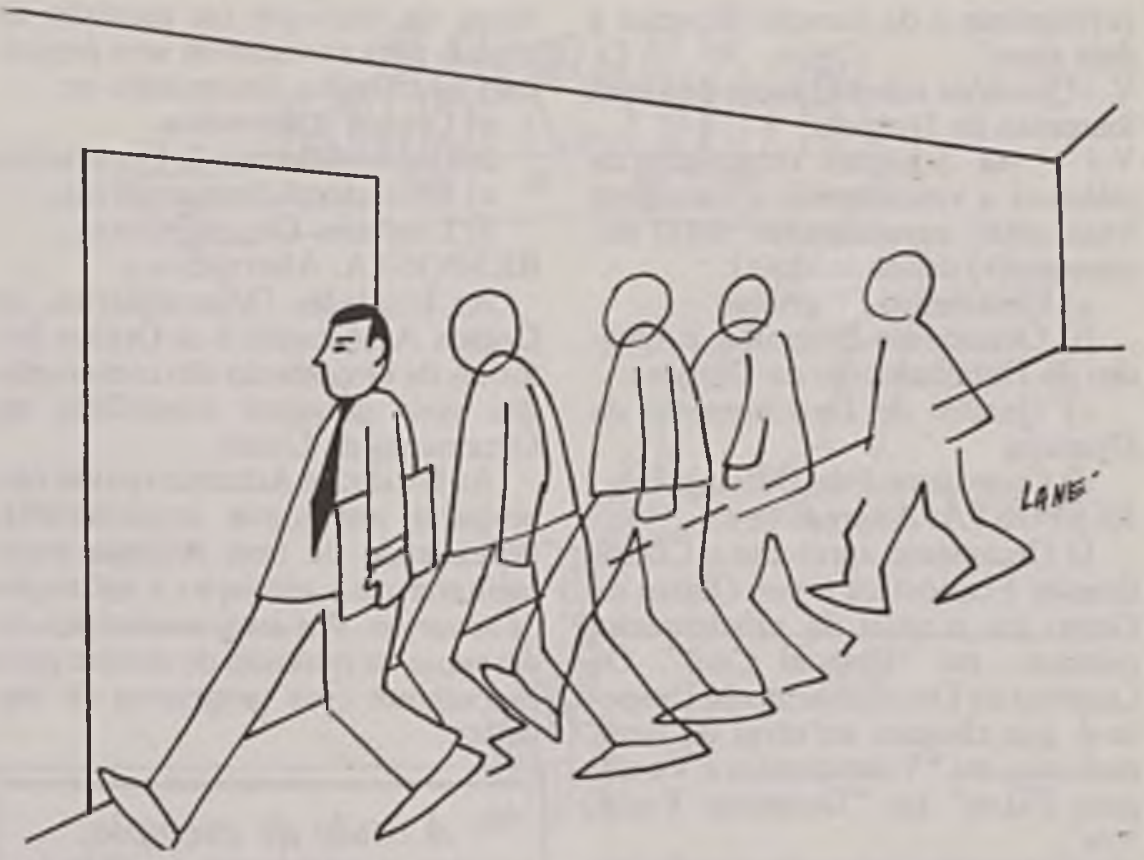

Aumento de Capital de Empresas Industriais ou Agricolas.

IV.3.2 - A despesa da União com o pagamento de salário-familia, a funcionários, è classificada na subcategoria económica denominada:

a) Despesas de Custeio.

b) Transferências Correntes.

c) Inversōes Financeiras.

d) Transferéncias de Capital.

RESPOSTA: Alternativa $b$.

O salário-familia é um subelemento de Transferencias a Pessoas, que integra as Transferências Correntes. IV.4 - Classificação por Objeto de Gasto

IV.4.1 - O dispêndio do Estado com o pagamento de Ajuda de Custo a funcionários estatutários integra a Natureza de Despesa denominada:

a) Pessoal Civil.

b) Transferèncias a Pessoas.

c) Remuneração de Serviços Pessoais.

d) Obrigaçōes Patronais.

RESPOSTA: Alternativa $a$.

Ajuda de Custo integra o subelemento Pessoal Civil, conforme o Adendo I à Portaria SOF No 8, de 04 de fevereiro de 1985.

IV.4.2 - O dispèndio do Estado com o pagamento de salário de servidores regidos pela Consolidação das Leis do Trabalho - CLT integra a Natureza de Despesa denominada:

a) Pessoal Civil.

b) Transferências a Pessoas.

c) Remuneração de Serviços Pessoais.

d) Obrigaçōes Patronais.
RESPOSTA: Alternativa $a$.

Salários de pessoal regido pela Consolidação das Leis Trabalhistas CLT integram o subelemento Pessoal Civil, de acordo com o Adendo I à Portaria SOF N: 8/85.

IV.4.3 - Quando o Estado compra um imóvel necessário à realizaçãc de obras, deve classificar a despesa no elemento denominado:

a) Material de Consumo.

b) Serviços de Terceiros e Encargos.

c) Aquisição de Imóveis.

d) Obras e Instalações.

RESPOSTA: Altemativa $d$.

O elemento de despesa Obras e Instalações inclui a aquisição de imóveis necessários à realizaçāo de obras, segundo o Adendo I à Portaria SOF No $8 / 85$.

A alternativa $c$ é descartada porque, na citada Portaria SOF, consta em Aquisição de Imóveis: "Exceto àqueles necessários à realização de obras".

IV.4.4 - De acordo com a Lei n. 4.320/64, o material adquirido pelo Estado deve ser classificado como Material Permanente quando sua duração for superior a:
a) um ano;
b) dois anos;
c) três anos;
d) quatro anos.

RESPOST A: Alternativa $b$.

O Art. 15 da Lei no 4.320/64 estabelece:

"§ 20 Para efeito de classificação da despesa, considera-se material 


\section{IDÉIAS}

permanente o de duração superior a dois anos".

V - Questões sobre Quadro de Detalhamento de Despesa:

V.1 - As dotações orçamentárias relativas a vencimentos e vantagens fixas estão especificadas no(s) documento(s) denominado(s):

a) Orçamento-Programa;

b) Orçamento-Programa e Quadro de Detalhamento da Despesa;

c) Quadro de Detalhamento da Despesa;

d) Cronograma de Desembolso.

RESPOSTA: Alternativa $c$.

O Orçamento apresenta a Classificação Econômica e por Objeto de Gasto até o nivel de subelemento, portanto, até "Pessoal Civil". Os Quadros de Detalhamento da Despesa é que chegam ao nivel de item, portanto, ate "Vencimentos e Vantagens Fixas" ou "Despesas Variáveis".

VI - Questões sobre Exercicio Financeiro:

VI.1 - A Lei no 4.320/64 dispõe que pertencem ao exercicio financeiro:

a) as despesas nele legalmente empenhadas e as receitas nele estimadas;

b) as despesas nele legalmente empenhadas e as receitas nele arrecadadas;

c) as receitas nele arrecadadas e as despesas nele liquidadas;

d) as despesas nele legalmente empenhadas e as despesas nele recolhidas.

RESPOSTA: Alternativa $b$.

A Lei no 4.320/64 adota o regime de caixa para as receitas e de competência para as despesas:

"Art. 35. Pertencem ao exercício financeiro:

I - as receitas nele arrecadadas;

II - as despesas nele legalmente empenhadas."

A alternativa $a$ é excluida porque fala em receitas estimadas, quando a lei prescreve a arrecadação.

A alternativa $c$ é descartada porque considera as despesas liquidadas, quando a lei exige apenas o empenho - a liquidaçào é outro estágio da despesa.

A alternativa $d$ nào menciona as receitas e inclui "despesas recolhidas".

VII - Questões sobre Estrutura do Sistema Orçamentário:

VII.1 - As repartiçōes da Administração Direta que, por não serem contempladas com dotaçōes especificas no Orçamento da União, neces- sitam de destaque ou provisão de crédito para executarem seus programas de trabalho denominam-se:

a) Órgãos Autónomos.

b) Órgãos Setoriais de Orçamento.

c) Unidades Administrativas.

d) Unidades Orçamentárias.

RESPOSTA: Alternativa $c$.

As Unidades Orçamentárias, os Órgãos Autônomos e os Órgãos Setoriais de Orçamento são contemplados com dotações especificas no Orçamento da União.

As Unidades Administrativas não possuem autonomia orçamentária, dependendo de uma unidade orçamentária para obtenção e aplicação de recursos. Por isso, necessitam de destaque ou provisão de crédito para executarem seus programas de trabalho.

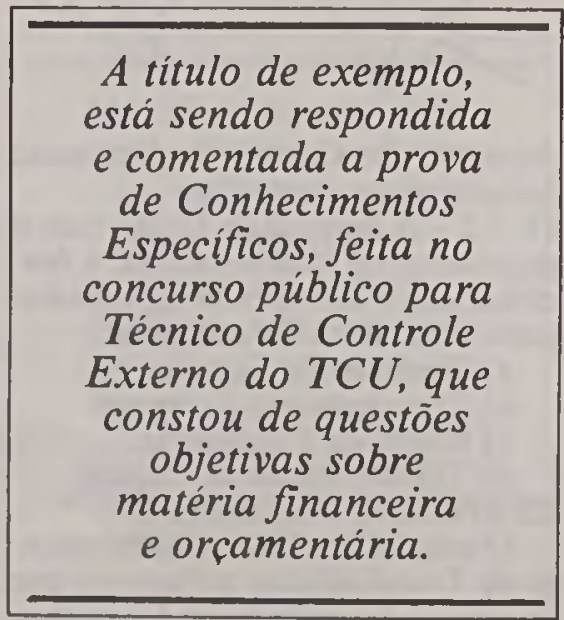

VIII - Questōes sobre Execução Orçamentária:

VIII.1 - Descentralização de Créditos VIII.1.1 - A descentralização de crédito orçamentário de Encargos Gerais da União - Recursos sob a Supervisão da Secretaria de Planejamento da Presidência da República$S E P L A N$, para a propria $S E P L A N$, é feito por:
a) repasse;
b) sub-repasse;
c) provisão;
d) destaque.

RESPOSTA: Alternativa $c$.

A provisão de créditos orçamentários é realizada dentro do proprio Ministerio ou Órgão para unidade administrativa diretamente subordinada ou para outras unidades orçamentárias ou administrativas não subordinadas.

As alternativas $a$ e $b$ referem-se a movimentação de recursos financeiros.
VIII.1.2 - A descentralização de Crédito Orçamentário de Encargos Gerais da União - Recursos sob a supervisão da SEPLAN para o Ministério da Fazenda é feito por:
a) repasse;
b) sub-repasse;
c) provisão;
d) destaque.

RESPOSTA: Alternativa $d$.

$\mathrm{O}$ destaque de créditos orçamentários é efetuado de um Ministério ou Órgão para outro Ministério ou Órgão. VIIII.2 - Movimentação de Recursos Financeiros

VIII.2.1 - Os repasses destinados a atender despesas orçamentárias estão sempre vinculados a um(a):
a) destaque;
b) provisão;
c) despesa de pessoal;
d) tributo.

RESPOSTA: Alternativa $a$.

Segundo a Instrução Normativa SECIN/SEPLAN/PR No 4, de 03 de setembro de 1981: "11. Chamase Repasse a importancia que a unidade orçamentária transfere a outro Ministério ou Órgão. A figura do Repasse financeiro está associada ao destaque orçamentário".

VIII.2.2 - Os cronogramas de desembolso tratam especificamente de:

a) dotações orçamentárias;

b) recursos financeiros;

c) provisão de crédito;

d) destaque de crédito.

RESPOSTA: Altemativa $b$.

Os cronogramas de desembolso têm por finalidade demonstrar os desembolsos necessários, por periodos, objetivando uma adequada utilização dos recursos financeiros. $O$ órgào central de programação financeira do Tesouro Nacional, após aprovar os cronogramas de desembolso, procede à liberação das cotas de recursos financeiros.

A alternativa $a$ trata de dotaçōes orçamentárias, enquanto as alternativas $c$ e $d$ referem-se à descentralização de créditos orçamentários.

VIII.3 - Licitação

VIII.3.1 - A modalidade de licitação que só podem participar interessados previamente registrados denominase:

a) concorrência;

b) tomada de preços;

c) convite;

d) dispensa.

\section{RESPOSTA: Alternativa $b$.}

Dizia o Decreto-lei No 200/67:

"Art. 127. São modalidades de licitação: 


\section{IDÉIAS}

I - A concorrência;

II - A tomada de preços;

III - O convite.

§ 30. Tomada de preços é a modalidade de licitação entre interessados previamente registrados, observada a necessária habilitação."

O Decreto-lei No 2.300 , de 21/11/86 estabelece:

"Art. 20. São modalidades de licitação:

I - concorrência;

II - tomada de preços;

III - convite;

IV - concurso;

$\mathrm{V}$ - leilão.

$\S 2$. Tomada de preços é a modalidade de licitação entre interessados previamente cadastrados, observada a necessária qualificação."

VIII.4 - Estágios da Despesa VIII.4.1 - Quando uma unidade orçamentária for emitir dois empenhos, sendo um para atender despesas não quantificáveis e o outro para atender despesas relativas a um contrato de manutenção de máquinas de escrever, no valor de $C_{2} \$ 60.000,00$, com duração de um semestre e pagamento de $\mathrm{Cz} \$ 10.000,00$ por mês, deve classificar os citados empenhos, respectivamente, nos tipos denominados:

a) estimativa e ordinario;

b) global e estimativa;

c) estimativa e global;

d) ordinário e estimativa.

RESPOSTA: Altemativa c.

Diz o Art. 60 da Lei no 4.320/64:

" $\S 2$. . Será feito por estimativa o empenho da despesa cujo montante não se possa determinar.

§3\%. E permitido o empenho global de despesas contratuais e outras sujeitas a parcelamento."

VIII.4.2 - No segundo estágio da despesa orçamentária, ocorre:

a) o empenho da despesa;

b) a extinção da obrigação do estado; pesa;

c) o lançamento contábil da des-

d) a verificação do direito adquirido pelo credor.

RESPOSTA: Alternativa $d$.

A despesa passa por très fases: empenho, liquidação e pagamento.

A Lei n: 4.320 conceitua:

"Art. 58. O empenho de despesa é 0 ato emanado de autoridade competente que cria para o Estado obrigação de pagamento pendente ou nào de implemento de condição.

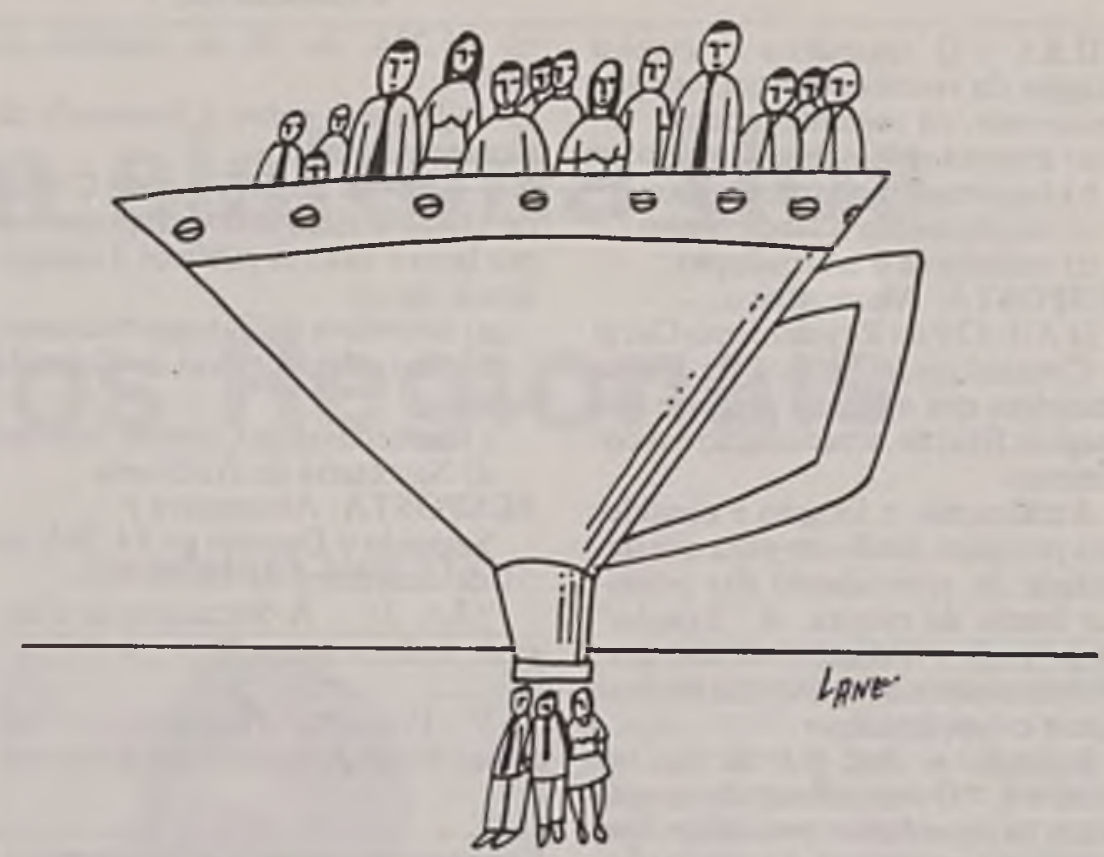

Art. 63. A liquidação da despesa consiste na verificação do direito adquirido pelo credor, tendo por base os titulos e documentos comprabatórios do respectivo crédito."

VIII.5 - Créditos Adicionais

VIII.5.1 - Os únicos créditos adicionais que podem ser reabertos, nos limites dos saldos existentes no final do exercicio em que foram autorizados, são:

a) suplementares e especiais, quando a autorização ocorrer nos últimos dois meses do exercicio;

b) suplementares e especiais, quando a autorização ocorrer nos últimos quatro meses do exercício;

c) especiais e extraordinários, quando a autorização ocorrer nos últimos dois meses do exercício;

d) especiais e extraordinários, quando a autorização ocorrer nos últimos quatro meses do exercicio.

RESPOSTA: Alternativa $d$.

Determina o Art. 62 da Constituição da República Federativa do Brasil:

" $\S 4$. Os créditos especiais e extraordinários não poderão ter vigência alèm do exercicio em que forem autorizados, salvo se o ato de autorização for promulgado nos últimos quatro meses daquele exercício, caso em que, reabertos nos limites dos seus saldos, poderão viger até o término do exercicio financeiro subseqüente."

VIII.6 - Suprimento de Fundos

VIII.6.1 - De acordo com as normas do Orgão Central de Controle Inter- no, nāo se concederá suprimento de fundos a servidor que:

a) seja subordinado ao ordenador de despesa;

b) exerça cargo de confiança;

c) não esteja em efetivo exercicio;

d) não tenha estabilidade.

RESPOSTA: Alternativa $c$.

A alternativa $a$ é eliminada porque a Instrução Normativa SECIN/SEPLAN/PR/N: 4, de 03 de setembro de 1981: "18. O titular de unidade orçamentária ou administrativa autorizará a entrega de suprimento de fundos exclusivamente a servidor subordinado."

Por outro lado, as despesas passiveis de realização através de suprimento de fundos exigem que o servidor esteja em efetivo exercicio.

VIII.7 - Restos a Pagar

VIII.7.1 - Os Restos a Pagar são classificados em:

a) orçamentários e extra-orçamentarios;

b) processados e não processados;

c) do ano anterior e de outros exercicios;

d) direto e indireto.

RESPOSTA: Altemativa $b$.

De acordo com a Lei n? 4.320/64:

"Art. 36. Consideram-se Restos a Pagar as despesas empenhadas mas não pagas até o dia 31 de dezembro, distinguindo-se as processadas das não processadas."

VIII.8 - Estágios da Receita 


\section{IDÉIAS}

VIII.8.1 - O segundo e o terceiro estágios da receita ocorrem, obrigatoriamente, na seguinte ordem:

a) arrecadação e recolhimento;

b) lançamento e arrecadação;

c) recolhimento e lançamento;

d) estimativa e arrecadação.

RESPOSTA: Alternativa $a$.

O Art. 139 do Regulamento Geral de Contabilidade Pública da União estabelece que a receita percorre três estágios: fixação, arrecadação e recolhimento.

Atualmente, a fixação é considerada previsão, tendo em vista a instabilidade na arrecadação das principais fontes de receita. A "fixação" compreende a realização de dois atos de escrituração: o registro das estimativas e o lançamento.

Segundo o Art. 53 da Lei n. 4.320/64, "O lançamento da receita é o ato da repartiçáo competente, que verifica a procedência do crédito fiscal e a pessoa que lhe é devedora e inscreve o debito desta. Portanto, o lançamento - que integra o primeiro estágio da receita - elimina as alternativas $b$ e $c$.

A estimativa tambem integra o primeiro estágio da receita, excluindo a alternativa $d$.

O segundo estágio da receita é a arrecadação - recebimento da receita pela repartição competente - e o terceiro é o recolhimento - transferência do produto da arrecadaçāo das receitas, da rede arrecadadora para o Banco do Brasil que é o agente financeiro do Tesouro Nacional.

IX - Questōes sobre a Secretaria do Tesouro Nacional.

IX.1 - Elaborar normas gerais de Administração Financeira, Contabilidade e Auditoria é competencia $\mathrm{da}(\mathrm{s})$ :

a) Secretaria do Tesouro Nacional;

b) Secretaria Central de Controle Interno:

c) Secretarias de Controle Interno;

d) Secretaria de Auditoria.

RESPOSTA: Alternativa $a$.

De acordo com o Decreto n. 92.452 , de 10 de março de 1986, a Secretaria do Tesouro Nacional passou a exercer a função de Órgão Central dos Sistemas de Administração Financeira, Contabilidade e Auditoria, tendo assumido as competências da Secretaria Central de Controle Interno, dentre as quais "IV elaborar normas gerais de administração financeira, contabilidade e auditoria..." (Art. 13 do Decreto n. 85.234 , de 06 de outubro de 1980).

$\mathrm{X}$ - Questōes sobre a Secretaria de Controle Interno

X.1 - Enviar ao Tribunal de Contas da União a relação dos responsáveis por bens e valores públicos é competência da(s):

a) Secretaria do Tesouro Nacional;

b) Secretaria Central de Controle Interno;

c) Secretarias de Controle Interno;

d) Secretaria de Auditoria.

RESPOSTA: Alternativa $c$.

Segundo o Decreto n. 84.362, de 31 de dezembro de 1979:

"Art. 3:. - A Secretaria de Controle Interno compete:

V-Promover a elaboração do rol anual dos responsáveis por dinheiros,

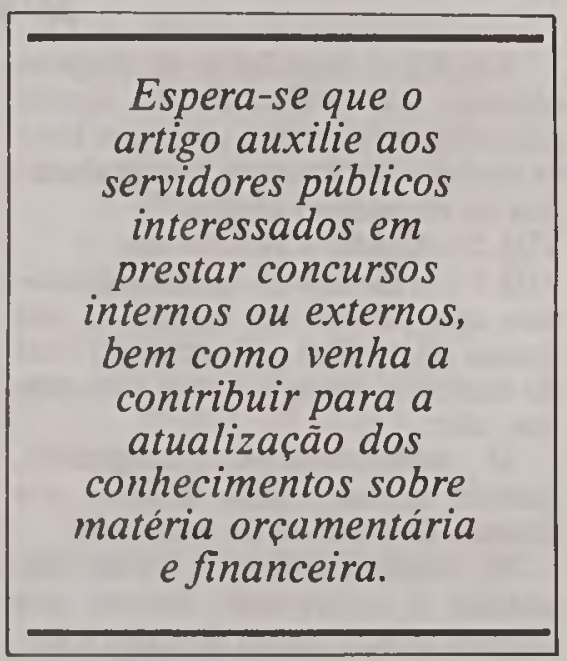

valores e bens públicos e, trimestralmente, as alteraçoes havidas no periodo... para controle e remessa ao Tribunal de Contas da União."

XI - Questōes sobre Contas do Governo

XI.I - O Presidente da República tem a atribuição de encaminhar as Contas do Governo Federal, relativas ao exercicio anterior, ao:

a) Congresso Nacional, até 60 dias após a abertura da Sessão Legislativa:

b) Congresso Nacional, até 60 dias após o inicio do exercicio financeiro;

c) Tribunal de Contas da União, até 60 dias após o inicio do exercicio financeiro;

d) Tribunal de Contas da União, até 60 dias após a primeira reunião.
RESPOSTA: Altemativa $a$.

A Constituição da República Federativa do Brasil estabelece:

"Art. 81. Compete privativamente ao Presidente da República:

XX - Prestar anualmente ao Congresso Nacional, dentro de sessenta dias após a abertura da sessão legislativa, as Contas relativas ao ano anterior;",

XII-Questōes sobre Compromissos em Moeda Estrangeira

XII. 1 - A inobservância da prioridade de pagamento dos compromissos em moeda estrangeira, assumidos pela Administração Federal, poderá ser considerada ato irregular de gestão, a critério do:

a) Ministro da Fazenda;

b) Tribunal de Contas da União;

c) Banco Central do Brasil;

d) Conselho Monetário Nacional. RESPOSTA: Alternativa $b$.

Dispõe o Decreto-lei n. 1.928, de 18 de fevereiro de 1982:

"Art. 1.. O pagamento, nos respectivos vencimentos, dos débitos decorrentes de compromissos em moeda estrangeira, que contarem ou não com a garantia do Tesouro $\mathrm{Na}$ cional, por fiança ou aval, outorgada diretamente ou concedida por intermedio de instituição financeira oficial, tera prioridade absoluta nos cronogramas financeiros de desembolso dos órgãos da administração indireta e suas subsidiárias, bem como das fundações instituidas ou mantidas pe-

lo Poder Público, que hajam assumido tais compromissos.

Art. 4:.....

Parágrafo Único. A inobservância da prioridade de pagamento de que trata o artigo 1. poderá, a critério do Tribunal de Contas da União, ser considerada ato irregular de gestão e acarretar para os infratores inabilitação temporária para o exercicio de cargo em comissão ou função de confiança nos órgãos ou entidades da administração direta ou indireta e nas fundações sob supervisão ministerial."

Espera-se que o presente artigo auxilie a todos os servidores públicos interessados em prestar concursos internos ou externos, bem como venha contribuir para a atualizaçào dos conhecimentos de todos aqueles direta ou indiretamente interessados em matéria financeira e orçamentảria. 